\title{
Proximidad espacial e integración social: aportes y debates desde Quito*
}

Spatial Proximity and Social Integration:

Contributions and Debates from Quito

Proximidade espacial e integração social:

aportes e debates desde Quito

\section{Cristhian Parrado Rodríguez ${ }^{*}$}

Recibido: 20 de septiembre de 2018

Aprobado: 3 de diciembre de 2019

https://doi.org/10.12804/revistas.urosario.edu.co/territorios/a.7296

Para citar este artículo:

Parrado Rodríguez, C. (2020). Proximidad espacial e integración social: aportes y debates desde Quito. Territorios (43), 1-31. https://doi.org/10.12804/revistas.urosario.edu.co/territorios/a.7296

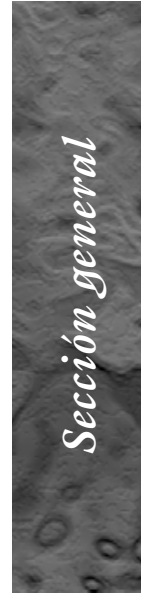

* El artículo muestra resultados de investigación de la tesis de Maestría en Estudios Urbanos que el autor desarrolló en Flacso Ecuador, la cual lleva como título: "Segregación y mezcla social: relaciones entre grupos de distinta condición socioeconómica en áreas socialmente diversas de Quito”. Agradezco la colaboración de Andrea Cevallos en la realización de los mapas que acompañan al articulo y el apoyo de Jorge Núñez y del Centro de Investigación Etnográfica de la Universidad de Cuenca y Flacso Ecuador en la escritura de la versión final del texto.

** Grupo FARO (Ecuador). Correos electrónicos: crparrador@gmail.com, cparrado@grupofaro. org. ORCID: https://orcid. org/0000-0001-7622-2599 
Palabras clave

Integración social; mezcla social; proximidad espacial; segregación.

Keywords

Social integration; social mix; spatial proximity; segregation.

Palavras-chave

Integração social; mistura social; proximidade espacial; segregação.

\section{territarias 43}

RESUMEN

Este artículo explora cómo influye la proximidad espacial en la construcción de vínculos sociales entre hogares de distinta condición socioeconómica en Quito. Se enfoca en un área específica del noroccidente de la ciudad, donde recientemente se generó una alianza intergrupal entre sus residentes para oponerse a un proyecto público de movilidad. A partir de una lectura multidimensional de la integración socioespacial, se analizan los efectos que tiene la mixtura social de esta área en: la conformación de oportunidades educativas y laborales; la interacción y construcción de relaciones sociales; y la identificación con un territorio común. Los hallazgos revelan que la proximidad de los hogares incide positivamente en la formación de vínculos sociales, la percepción sobre el otro y en la filiación con el territorio, esto particularmente a partir de respuestas políticas intergrupales donde se privilegia el espacio compartido en lugar de la diferencia socioeconómica. De esta manera, el artículo invita a incorporar el vínculo político para reflexionar la integración social en la ciudad latinoamericana.

\section{ABSTRACT}

This article explores how spatial proximity influences the construction of social bonds between households of different socioeconomic conditions in Quito. It focuses on a specific area of the northwest of the city, where recently an intergroup alliance was created among its residents to oppose a public mobility project. From a multidimensional reading of socio-spatial integration, the effects of the social mixture of this area are analyzed in: the creation of educational and labor opportunities, the interaction and construction of social relations, and the identification with a common territory. The findings reveal that the proximity of households has a positive impact on the formation of social bonds, the perception of the other and on the affiliation with the territory, this particularly from intergroup political responses where the shared space is privileged instead of the socioeconomic difference. In this way, the article invites to incorporate the political link to consider social integration in the Latin American city.

\section{RESUMO}

Este artigo explora como influi a proximidade espacial na construção de vínculos sociais entre lares de diferente condição socioeconômica em Quito. Enfoca-se em uma área específica do noroeste da cidade, onde recentemente se gerou uma aliança intergrupal entre residentes para se opor a um projeto público de mobilidade. A partir de uma leitura multidimensional da integração socioespacial se analisam os efeitos que tem a mistura social desta área na: conformação de oportunidades educativas e laborais, na interação e construção de relações sociais, e na identificação com um território comum. Os resultados revelam que a proximidade dos lares incide positivamente na formação de vínculos sociais, a percepção sobre o outro e na filiação com o território, isto particularmente a partir de respostas políticas intergrupais onde se privilegia o espaço partilhado em vez da diferença socioeconômica. Desta maneira, o artigo convida a incorporar o vínculo político para refletir a integração social na cidade latino-americana. 


\section{Introducción}

Este artículo busca explorar cómo influye la proximidad espacial en la construcción de vínculos sociales entre hogares de distinta condición socioeconómica. Para Latinoamérica, esta proximidad en principio hace alusión a la coexistencia de hogares de distintos niveles de ingresos en un mismo espacio (Sabatini, 2015; Rodríguez \& Arriagada, 2004). Es decir, son lugares en los que vecindarios y viviendas de ingresos bajos, medios y altos comparten fronteras geográficas entre sí.

La literatura regional ha logrado un relativo consenso sobre la producción de esta proximidad, pues asume que, a partir del dinamismo del mercado inmobiliario y la construcción de conjuntos cerrados en las periferias populares, ocurre una cercanía entre diferentes grupos (Sabatini, 2015). Por su parte, la experiencia de cercanía espacial en ciudades europeas y estadounidenses se ha dado en el marco de la aplicación de diversas políticas públicas que proponen la conformación de espacios residenciales más heterogéneos, esto como medida para revertir los efectos negativos de la segregación y la pobreza concentrada (Colomb, 2011; Chaskin \& Joseph, 2010 ). En todo caso, y pese a la diferencia entre ambos contextos territoriales, a nivel general la literatura más tradicional considera que la proximidad potencia procesos de "integración socioespacial" (Ruiz-Tagle, 2013), término con el cual se define principalmente la configuración de vínculos sociales entre grupos sociales diferentes que habitan en una misma área residencial.

Antes de hacer una revisión exhaustiva de los enfoques y aproximaciones teóricas a la integración social, que ya ha sido realizada en otros trabajos (véase a RuizTagle, 2016a), en este artículo interesa resaltar su carácter multidimensional. Por un lado, para Sabatini y Salcedo (2007), la integración contempla tres dimensiones: una funcional, que consiste en la integración al mercado de consumo o de trabajo; una comunitaria, relacionada con la construcción de redes sociales; y otra simbólica, asociada al sentido de pertenencia y arraigo de los grupos al lugar. Por su parte, Ruiz-Tagle (2013, p. 401) entiende la integración como una relación multidimensional que puede funcionar de manera independiente y en distintos niveles a través de cuatro dimensiones: física, funcional, relacional y simbólica. La primera referida a la proximidad entre grupos diferentes. La segunda alusiva al acceso efectivo a oportunidades y servicios. La tercera basada en interacciones y relacionamiento entre grupos. Y la cuarta apoyada en la identificación con un territorio común.

Este artículo se ubica analíticamente sobre esta última lectura multidimensional de la integración para analizar los efectos que tiene la proximidad espacial en tres aspectos: 1) la conformación de oportunidades educativas y laborales ( $\mathrm{di}^{-}$ mensión funcional); 2) la interacción y territarias 43 
construcción de relaciones (dimensión relacional); 3) y la percepción del otro y la identificación con un territorio común (dimensión simbólica). Esta distinción permite diferenciar y caracterizar el tipo de impacto que genera la proximidad física en la construcción de múltiples vínculos posibles entre los grupos.

Sin embargo, pese a que la bibliografía y experiencia internacional sobre proximidad entre grupos resulta ser abundante, esta no ha podido llegar a un consenso en específico. Por un lado, algunas posiciones indican que la proximidad puede generar consecuencias positivas - en especial-a los hogares de menores ingresos, en la medida que implica mejores oportunidades de trabajo y educación (Basolo, 2013), desarrollo de sentimientos de superación social (DeLuca, et al., 2012), así como también mayores relaciones sociales con grupos de diferente condición social (Musterd \& Ostendorf, 2006) y la disminución de estigmas socioterritoriales (Sabatini \& Salcedo, 2007; Morandé, 2007). Por el otro, otras posiciones señalan que la proximidad no implica necesariamente mayores niveles de convivencia e interacción entre los grupos. Antes bien, reconocen que la cercanía muchas veces viene asociada con la existencia de brechas sociales estructurales que no permiten el contacto (Ruiz-Tagle, 2016b; Bolt et al., 2010). Por lo tanto, consideran un error que se siga pensando revertir con la proximidad espacial los problemas de segregación y pobreza que sobrellevan ciertas poblaciones de bajos ingresos (DeFilippis, 2013; Imbroscio, 2012). Además, cuestionan que esta tenga una mirada vertical de arriba-abajo en la que solamente se benefician los estratos bajos a partir de las redes, conductas y normas de los estratos altos (Ruiz-Tagle, 2016a).

En este debate interesa resaltar la posición que asumen algunos autores que cuestionan el determinismo espacial en muchas políticas públicas que promueven la mezcla social (Kearns, et al., 2013). Estos discuten que la integración social de poblaciones pobres sea pensada y reducida simplemente a una cuestión de estar en proximidad con otros grupos de mejor condición socioeconómica. Afirmación que involucra supuestos asociados a que estos hogares no viven en áreas de oportunidad (Imbroscio, 2012), o que la proximidad geográfica lleva a mejorar y aumentar su capital social (DeFilippis, 2013). Aunque estos autores no abandonen la idea de lograr una mayor heterogeneidad en las áreas residenciales, apelan por nuevos paradigmas que no exageren la importancia del espacio para disminuir las brechas sociales y generar relacionamiento entre grupos.

Empero, más allá de sus diferencias teóricas, las distintas posturas comparten que es necesario identificar cómo ocurren las relaciones sociales entre diferentes en el marco de la cercanía física. Esto en función de clarificar los efectos que tiene la proximidad y, además, de describir las distintas capacidades y estrategias con las que los grupos sociales pueden resistirse 
o beneficiarse en un contexto de vecindad (Rasse, 2015; Chaskin \& Joseph, 2010). Un acercamiento necesario para indagar por la experiencia cotidiana y la construcción de significados que se producen en el espacio compartido.

En este contexto, este artículo estudia la integración socioespacial en un área residencial de Quito (Ecuador), donde ocurre una proximidad física entre grupos de distinta condición socioeconómica. La hipótesis principal sostiene que la proximidad incide positivamente en la construcción de lazos, la percepción sobre el otro y en la identificación con el territorio, esto particularmente a partir de respuestas políticas y alianzas intergrupales donde se privilegia el espacio compartido en lugar de la diferencia socioeconómica. No obstante, como se verá en los siguientes apartados, esta proximidad o esta alianza no implica que los distintos grupos compartan espacios educativos o generen mayores oportunidades laborales entre sí. Aspectos que invitarán a reflexionar sobre las posibilidades y límites de la integración social en la ciudad.

\section{Quito y el área del \\ Condado: caso y método}

Durante el siglo Xx la ciudad de Quito experimentó una conformación de un orden urbano segregado basado en una diferenciación entre el norte y el sur (Carrión, et al., 1978; Achig, 1983; Carrión, 1987): en las zonas del norte se ubicaron las poblaciones de más altos ingresos de la ciudad, mientras que en las del sur se localizaron las de menores recursos económicos. Sin embargo, esta distinción norte-sur como lugares de oposición y ocupación diferenciada de las clases se reinterpreta cuando se entiende que en ambos escenarios ha habido una suerte de mezcla social (Santillán, 2015), incluso desde mediados del siglo XIX, pese al interés de ocultar e higienizar al otro (Kingman, 2006). En especial, el desarrollo de procesos de urbanización a mitad del siglo XX a partir de la Reforma Agraria posibilitó el surgimiento de diferentes áreas internas de la ciudad donde se configuró la presencia de hogares de distinta extracción social. Este tipo de proceso se basó en la lotización de diversas haciendas, donde algunos terrenos fueron obsequiados a los sectores más pobres de la sociedad - conocidos como huasipungueros — ${ }^{1}$ mientras otros se reservaron para la construcción de lugares de residencia de estratos medios y altos (Regalado, 2015). Así, este tipo de desarrollo no solo estructuró el paisaje urbano de grandes porciones de Quito, también generó situaciones de proximidad entre hogares de distinto nivel socioeconómico.

No obstante, esta proximidad y sus efectos en términos de integración social no han sido abordados de manera profunda por la literatura local. A grandes rasgos existen trabajos que desde una perspectiva etnohistórica (Kingman, 2006) o contemporánea (Ron, 2017; López, 2012) han mencionado las dinámicas de convivencia,
Esquema laboral que consistia en que el hacendado prestaba tierras a indigenas (buasipungueros) a cambio de trabajo.

territarias 43 
sociabilidad y conflicto que ocurren entre grupos diferentes. Principalmente, en años recientes se nota un especial interés por estudiar las dinámicas de crecimiento de la ciudad que impactan profundamente la forma urbana y las relaciones sociales. Estos estudios pretenden dar cuenta de los conflictos, pugnas y contradicciones que suceden con la cercanía espacial de grupos socialmente diferentes a partir de movimientos residenciales, principalmente hacia los valles periféricos de la ciudad (López, 2017). Unos han revelado la existencia de pugnas que no son propiamente de clase, sino resultantes de la expresión del sistema de valores culturales (López, 2012); y otros han sacado a luz los procesos de acorralamiento de las formas de habitar y de reemplazamiento que sufren los pobladores tradicionales del periurbano (Ron, 2017; Durán et al., 2016). Aunque estos estudios no trabajen a partir del término integración social, sí evidencian una creciente preocupación por registrar la convivencia y el conflicto social que se produce en el marco de la proximidad espacial, pese a que la segregación en la ciudad sigue ocurriendo y se sigue estudiando en contextos a gran escala (Bermúdez, et al., 2016; Santillán, 2015).

Así, estos avances en la literatura local permiten afirmar que en Quito se experimentan condiciones de proximidad espacial que favorecen el encuentro entre grupos sociales diferentes. Por ejemplo, algunos estudios han mostrado que en función de una estratificación de la población por nivel educativo- existen áreas de la ciudad con un componente fuerte de heterogeneidad social (Parrado, 2018). Estas representan áreas potenciales de contacto en Quito que se sitúan en zonas urbanas y periurbanas, y manifiestan probabilidades medias y altas para que los estratos puedan encontrarse con hogares de diferente condición social. A nivel urbano, estas áreas se emplazan en la zona norte y en el centro-sur, donde grupos de distinta condición socioeconómica viven en un área reducida compartiendo las mismas condiciones físicas del entorno.

Bajo este contexto, para este artículo se consideró un área residencial potencial de contacto del noroccidente de Quito donde habitan hogares de distinta condición socioeconómica, la cual abarca al barrio San José del Condado (en adelante solo San José) y la Urbanización El Condado (en adelante solo la Urbanización). La escogencia de esta área se hizo a partir del diseño de estudio de caso (Gerring, 2007), el cual consideró cuatro pasos. Primero, se utilizó la base de datos del Censo de Población y Vivienda del año 2010 para estratificar la escolaridad de los jefes de hogar de la ciudad a nivel de manzana censal. Así como ocurre en diversos estudios (Molinatti, 2013; Sánchez, 2012; Sabatini, et al., 2010), el nivel educativo alcanzado por el jefe de hogar se emplea como variable proxy para dar cuenta de la segmentación económica de los grupos, la cual se aproxima al nivel de ingresos de los hogares en la medida 
que intenta representar sus potenciales entradas económicas. Segundo, se aplicó el índice de exposición de Bell (1954) sobre una base cartográfica para medir y detectar las áreas potenciales de contacto donde un hogar del nivel educativo bajo puede encontrarse con otros de diferente condición social. Esto permitió identificar áreas con probabilidades altas, medias, bajas o insignificantes para el encuentro entre diferentes estratos (Parrado, 2018). Se consideró que las probabilidades altas representan una mayor heterogeneidad del área (contactos posibles entre dos o más estratos). En cambio, probabilidades muy bajas o insignificantes reflejan una mayor homogeneidad social. Tercero, se ubicaron las áreas de mayor probabilidad de contacto de Quito donde el índice de exposición fue mayor, dando como resultado aquellas que se ubican en la zona norte (figura 1, parte izquierda). Y cuarto, siguiendo a Bryman (2007), se seleccionó al área de San José y la Urbanización por ser un caso representativo de la diversidad socioeconómica existente en el noroccidente de la ciudad (figura 1, parte derecha), a lo cual se sumó el criterio de oportunidad que tenía el investigador de interactuar con sus residentes a partir de su red de contactos.

En esta área, se realizó un trabajo de campo desde enero hasta junio de 2018 , donde se efectuaron un total de diez ejercicios de observación y se llevaron a cabo 16 entrevistas semiestructuradas, entre grupales e individuales, aplicadas a un total de 33 personas. Se empleó la observación como técnica cualitativa

Figura 1. Área de estudio

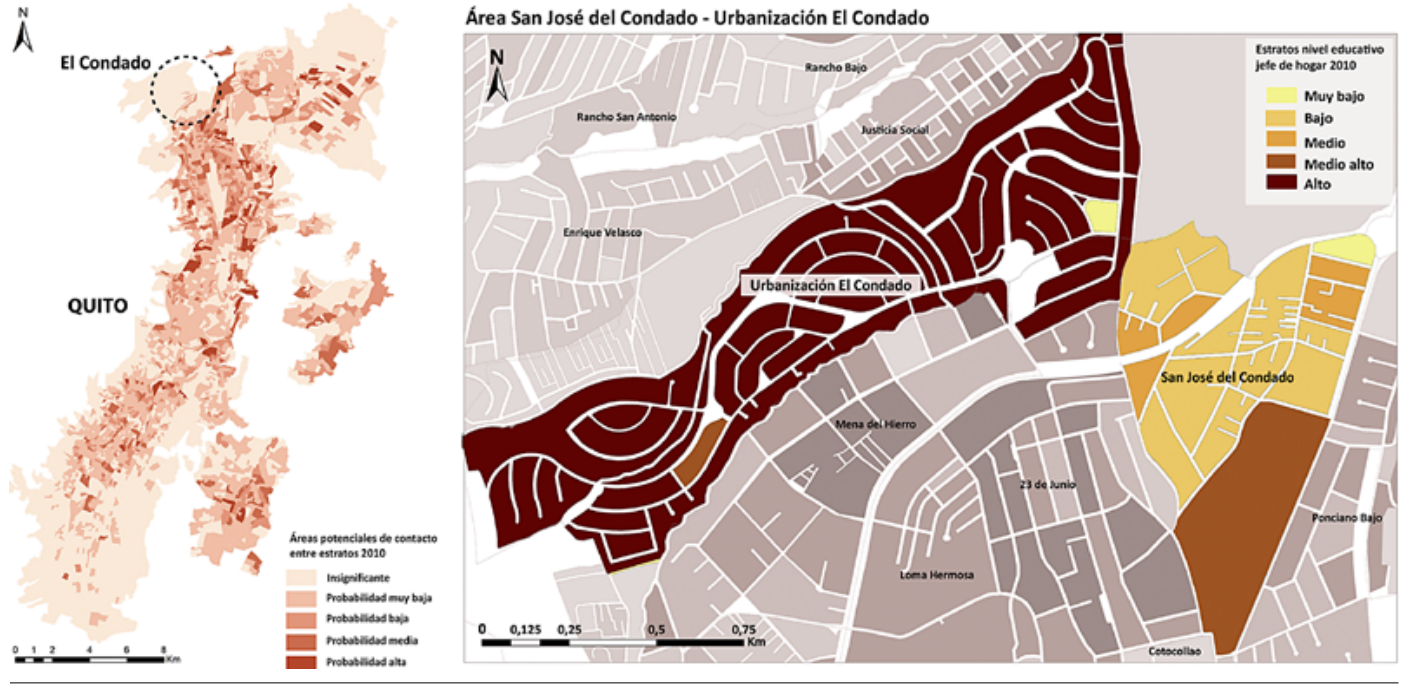

Fuente: INEC (2010). Elaboración del autor. 
(Ferro, 2010) para mapear y estudiar los espacios claves de encuentro de los grupos. Aquí se desarrollaron observaciones de aproximadamente tres horas cada una, donde se observó el comportamiento de los actores al tiempo que se hacían anotaciones, preguntas y registro fotográfico. Se usó la entrevista semiestructurada (Guber, 2004) aplicada a partir del método 'bola de nieve' con muestreo evaluado según edad, género, nivel educativo y años de permanencia. Las entrevistas tuvieron una duración promedio de dos horas cada una, y a través de ellas se llegó a un diálogo profundo con los actores para que describieran su experiencia de habitar en el área. Adicionalmente, durante la entrevista se mostraron imágenes que reflejan contextos de proximidad en Latinoamérica con el fin de que los entrevistados pudieran reflexionar en perspectiva comparada sobre la distancia social y la cercanía espacial.

Ahora bien, aclarado el componente metodológico del artículo, a continuación se describe el área de estudio. El área de San José y la Urbanización presenta una proximidad física entre hogares con niveles educativos bajos (educación primaria o menos), medios (entre educación secundaria y ciclo posbachillerato) y altos (educación superior y posgrado). Mientras que en la Urbanización se localizan niveles medioalto y alto, San José alberga entre niveles muy bajo y medio. La presencia de todos estos estratos genera en la actualidad una mixtura social que, incluso, es posible rastrear desde su misma conformación a comienzos del siglo XX cuando sus terrenos hacían parte de la Hacienda El Condado, los cuales se repartieron a partir de la Reforma Agraria. Los terrenos de peor calidad fueron dados a los huasipungueros, quienes terminan vendiéndolos a hogares de escasos recursos y estos, a su vez, formaron el barrio San José. Los de mejor calidad se reservaron hasta 1980 , momento en que surgió la Urbanización y los hogares de altos ingresos compraron algunos predios para edificar sus viviendas.

Estos dos momentos estuvieron marcados por la presencia del Quito Tenis y Golf Club, un equipamiento que se instaló a finales de 1970 con la intención de proveer un club deportivo a los sectores adinerados de la ciudad. Durante la década de 1990, la Urbanización realizó un cerramiento alrededor de su perímetro a la par que se presentó un auge de proyectos de vivienda en lotes grandes dirigidos hacia hogares de altos ingresos (Torres, 2015). En la actualidad se construyen nuevas viviendas que distan de parecerse a las primeras, debido a que se producen en lotes más pequeños y en serie, pero se continúa con el cerramiento que separa a la Urbanización de los barrios populares de su alrededor (Narváez, 2018). Paralelamente a esto, en San José se presenta un intenso mercado de arrendamiento de habitaciones o departamentos. A tiempo de hoy, y a raíz de la construcción del centro comercial Condado Shopping en 2007, se fortalecen estos dos procesos en ambos lugares (Ron, 2012). 
Esta área residencial presenta una característica particular, ya que los diferentes grupos se unieron a partir del rechazo al proyecto Quito Cables, el cual fue impulsado por el gobierno de Mauricio Rodas, alcalde de la ciudad entre 2014 y 2019. Quito Cables es un proyecto de transporte público tipo teleférico planteado en el año 2015 por la administración de Rodas. Basándose en los problemas de movilidad que presenta el noroccidente de Quito asociados a trancones y embotellamientos en las principales vías, el proyecto planteó la construcción de una línea de teleférico que conectara los barrios altos de esta área con la terminal de transporte del norte de la ciudad, para que formara parte del Sistema Integrado de Transporte Metropolitano y solucionara las dificultades de movilidad de la zona. Para la realización del proyecto, se contempló la expropiación de quince lotes en San José y la construcción de tres pilonas o torres en la Urbanización.

A partir de esta propuesta, ambos barrios se opusieron a Quito Cables. En un primer momento, la falta de información y socialización del proyecto implicó una oposición por parte de San José. En segundo lugar, la movilización del barrio aumentó en contra de la expropiación de los predios. A medida que avanzaba la organización barrial, ocurrió el encuentro entre los residentes de San José y los de la Urbanización. Estos últimos se oponían al proyecto, principalmente porque no querían la construcción de las pilonas y el tránsito del teleférico sobre las viviendas. Entre varios encuentros, las reivindicaciones puntuales de ambos barrios se transformaron en una común oposición al proyecto alrededor del frente “No Quito Cables", en tanto que para ambos grupos el proyecto no estaba sustentado en estudios técnicos, no se había efectuado una debida socialización y se habían vulnerado los derechos a la información y a la participación ciudadana. En los siguientes apartados se discuten los procesos de integración a partir de esta alianza intergrupal. Primero, se presentan los hallazgos de la dimensión funcional; luego, de la relacional; y, después, de la simbólica.

\section{Servicios segmentados y vínculos de empleo}

La literatura les otorga valor a las oportunidades y beneficios que se desprenden de la proximidad. Uno de estos se relaciona con la existencia de servicios educativos al que pueden acceder niños de los diferentes grupos (Basolo, 2013). La otra tiene que ver con la formación de vínculos de empleo, dado que miembros de los grupos pueden ejecutar contratos laborales (Morandé, 2007; Rosenbaum et al., 2002). En este apartado se discuten estos supuestos a partir de los hallazgos de la investigación, puesto que las oportunidades educativas son segmentadas, y si bien existen oportunidades laborales, estas son ocupadas mayoritariamente por residentes de otras zonas de la ciudad. territarias 43 
En relación con las oportunidades educativas, si bien es verdad que en el área de estudio se ubican varios colegios particulares y escuelas fiscales (que ofrecen desde grado de educación básica hasta bachillerato), el acceso a estas es segmentado, ya que los entrevistados de la Urbanización afirman enviar a sus hijos a los primeros y los niños de San José mayoritariamente acuden a las segundas. Esta segmentación escolar se experimenta por parte de los entrevistados en torno a tres aspectos, los cuales evidencian cómo existen limitaciones económicas, simbólicas y de intereses personales para generar beneficios y escenarios educativos con mezcla social en el área de estudio.

El primero hace alusión al costo de los colegios privados: los residentes de San José señalan los altos precios de matrícula y pensión de estas instituciones, factor que termina constituyendo una barrera de acceso para que sus hijos estudien en ellos. Aunque los entrevistados no indiquen la cuantía de estos colegios, esta en sí misma representa una frontera de orden simbólico con la cual se regulan las expectativas de mezcla educativa (DeLuca, et al., 2012). En sintonía con esto, el segundo aspecto se refiere a la búsqueda de instituciones de prestigio: los grupos no cualifican las oportunidades educativas alrededor de la existencia de entornos escolares en donde confluyan niños de diferentes estratos, sino valoran más la distinción o el reconocimiento que tiene la institución. Según los entrevistados, egresar de una institución de prestigio genera más oportunidades en lugar de titularse de una que no disponga de este capital simbólico. En el área residencial, son los colegios particulares quienes están mejor posicionados en la circulación del prestigio educativo, mientras que las escuelas fiscales disponen de baja popularidad: "Yo estudié en un colegio de monjas de por aquí arriba. Mis papás me enviaron a ese, para que saliera de un colegio de mayor renombre" (Grayce, residente de San José). Debido a esta condición de desventaja, algunos padres de familia que viven en San José optan por enviar a sus hijos a escuelas ubicadas en otra parte de la ciudad, para buscar el prestigio.

Finalmente, el tercer aspecto se relaciona con el sentimiento que origina el acceso de población de bajos recursos a colegios particulares: aunque los entrevistados de ambos grupos no abandonan la idea de generar acceso a habitantes de San José a estas instituciones, hacen mayor énfasis en mejorar la educación pública. Particularmente, los residentes de San José prefieren acceder a la educación por sus propios méritos, en lugar de hacerlo mediante programas de los colegios privados que permitan su ingreso, por ejemplo, a través de la reducción de costos de matrícula. Califican estos programas como medidas de caridad y no como una generación de verdaderas oportunidades. Que estos programas sean vistos como caridad envuelve implícitamente la aceptación de una relación vertical que, a ojos 
de los hogares de estratos bajos, debe ser rechazada. Esta actitud puede representar cómo determinados hogares buscan diferenciarse en función de su acceso personal a determinados colegios: este no debe regalarse, sino debe conseguirse. De esta manera, terminan resaltando el papel protagónico que debe tomar el Estado para reformar la calidad y la infraestructura de las escuelas fiscales, lo cual redundaría en un aumento de las oportunidades de la población que estudia en ella.

Ahora bien, con respecto a los vínculos de empleo, en el área se evidencia la existencia de contratos laborales entre los grupos. Los entrevistados de la Urbanización sostienen que generalmente brindan oportunidades relacionadas con el servicio doméstico, jardinería, carpintería y albañilería. Además, quienes cuentan con su propia empresa también aceptan personal para que se desempeñe en diferentes tareas. Aunque advierten que hay empleados que provienen de San José, no obstante, reconocen que no es la regla general. Es más, aseveran que la mayoría de sus trabajadores provienen de otras partes de la ciudad:

Yo tengo quince empleados. Tres viven en el sur. Una vive en el Valle de los Chillos. Seis viven en Calderón. Cuatro viven en La Roldós y Pisulí. Y otro que vive en Cumbayá. Entonces, son dispersos, unos viven en el sur, otros en el norte, otros en el valle, ninguno vive en el centro (Lothar, vocero de la Urbanización).
Así mismo, los residentes de San José manifiestan que no todos los que viven en el barrio trabajan con los hogares de la Urbanización: "Sí, hay gente que trabaja allá como empleadas domésticas, costureras, albañiles, carpinteros. Pero no todos. También hay gente que trabaja en otras partes o que viven del trabajo diario" (Sonya, residente de San José).

En función de esto, si bien se observan vínculos de empleo entre los grupos, los mismos residentes reconocen que estos ocurren independientemente de si se comparten las fronteras residenciales. Por un lado, las ofertas y contratos laborales que ofrece la Urbanización abarcan a toda la mano de obra existente en la ciudad, no únicamente la que se ubica en el entorno inmediato. $Y$, por el otro, la fuerza de trabajo de los residentes de San José también se emplea en otras actividades y lugares de la ciudad. En todo caso, aun cuando no se contrate a la población vecina, los vínculos de empleo entre los grupos tienden a ser vistos como necesarios: "Si te pones a pensar, son ellos los que más tienen la capacidad de dar trabajo. Tal vez por eso es que acudimos a ellos [risas], y ellos también acuden a nosotros [risas]. Como que nos necesitamos" (Andrés, residente de San José).

Así, se asume al mercado de trabajo como el marco de interpretación de las relaciones laborales, donde unos están en la capacidad de ofertar trabajo y otros buscan ser empleados en estas ofertas. Empero, esta mutua dependencia laboral territarias 43 
no es percibida como armónica. Antes bien, puede darse en el marco de contratos laborales inequitativos. Por ejemplo, en San José se afirma que algunos trabajos realizados a hogares de la Urbanización no han sido reconocidos por el dinero adecuado, el pago se retrasa e, incluso, nunca llega. Se califica esta conducta como un trato injusto y deshonesto, reconociendo igualmente que existen personas que no lo practican. Juicio similar hay sobre la falta de protección y seguridad social en los contratos. Debido a que en el año 2011 el gobierno ecuatoriano normó la obligación de afiliación social y el reconocimiento de horas extras en el servicio doméstico, quienes trabajan en esta rama o conocen casos de parientes o vecinos que lo hagan califican esta desprotección como una mala conducta, puesto que reconocen que existen casos similares donde ciertos habitantes - no todos - incumplen con este requisito legal, además de que realizan un mal trato hacia sus empleados: "Sí, hay gente que es déspota, grosera. No afilian a sus empleadas, tratan de minimizarlas, miran por encima del hombro, como: 'No, no, no, hazme esto'. Conozco un par de casos donde son así. Pero muy poca gente" (Carlos, residente de la Urbanización).

No obstante, este comportamiento no se asume como algo típico de la Urbanización, sino se observa como una conducta que caracteriza a los nuevos hogares que se han localizado en los últimos años. Estos hogares son considerados como clases sociales en ascenso que buscaron la
Urbanización para representar un estatus social que, de cualquier modo, no corresponde con el de los antiguos residentes:

Creo que eso ocurre más con los nuevos residentes. La gente que ya lleva toda su vida aquí no hace eso, tienen empleadas de 20 años y les pagan todo. No tratan mal a nadie. Son de lo más sencillo. En cambio, la nueva gente es lo contrario: quieren aparentar, se creen muy arriba, y sin ser, y sin tener. Y son estos los que no afilian o tratan mal a la empleada (Jaqueline, residente de la Urbanización).

Igualmente, algunas entrevistas sitúan la posesión del dinero como elemento importante dentro de la dependencia laboral. Este se asume como el factor que permite los vínculos de empleo. Se da por sentado que la posesión de dinero de los residentes de la Urbanización permite la contratación de personal. Sin embargo, los residentes de San José admiten que no todos los empleadores que poseen dinero generan un mismo trato. Identifican que los empleadores que han ascendido socialmente son los que ofrecen un trato más jerárquico, en comparación a los que siempre han tenido dinero:

La gente que siempre ha tenido dinero no le trata a uno con superioridad. Yo me he topado con gente que tiene mucha plata y es la gente más sencilla para tratar. O sea, no demuestran: "Ah, yo tengo harto". No. A ellos ni les va ni les viene, ya que toda

Cristhian Parrado Rodríguez 
la vida han tenido. En cambio, los que llegan a tener [pausa] quieren demostrar a todo mundo que tienen plata, que lo lograron. Tratan a la otra persona como minimizándola. Son gente de apariencia (Natalia, residente de San José).

De acuerdo con lo anterior, se identifica una población en movilidad social ascendente que altera los procesos de integración funcional. En el área no se cuestiona la existencia de ofertas y contratos laborales entre los grupos, sino se discuten las conductas de superioridad y apariencia que realizan algunos empleadores, específicamente quienes están en ascenso social. Estos son vistos como quienes generan vínculos de empleo basados en relaciones jerárquicas (tratos más diferenciados) y contratos deshonestos (sin seguridad social). Una actitud que influye en el sentimiento de oportunidad laboral en los contextos de mezcla social (Rosenbaum, Reynolds \& DeLuca, 2002).

\section{Interacciones precarias y lazos sociales}

Otro de los supuestos de la literatura sobre integración concede importancia a las interacciones sociales entre distintos grupos. Por un lado, se considera que la existencia de espacios públicos en las áreas con mezcla social posibilita encuentros más constantes entre los grupos (Fraser, Chaskin \& Bazuin, 2013; DeLuca, et al., 2012). Por el otro, se asume que con la proximidad espacial surge la proximidad social, la cual se refleja en relaciones de amistad o vecindad entre los residentes de distinto nivel socioeconómico (Joseph, 2006; Muster \& Ostendorf, 2006; Rosenbaum, et al., 2002). A continuación se discuten estos supuestos, debido a que en el área estudiada son escasos los encuentros intergrupales en los espacios públicos y hay dificultad de establecer relaciones de vecindad o amistad entre los diferentes estratos.

En cuanto a las interacciones en público, en el área residencial existen espacios potenciales de encuentro, como zonas de recreación, paradas de buses y centros comerciales, donde la viabilidad de acercamiento es reducida. Para empezar, las interacciones intergrupales en los espacios recreativos resultan ser pocos probables, ya que se desarrollan más entre miembros de un solo estrato que entre estratos. Esto debido a que cada barrio y grupo posee sus propios lugares para la recreación. En San José el único espacio es una cancha de fútbol, mientras que la Urbanización cuenta con un parque en su interior y también posee un acceso preferencial al club deportivo Quito Tenis y Golf Club. En las entrevistas se subraya lo remoto que resulta encontrarse con miembros de otros estratos en estos lugares:

Es que claro, ¿ cómo van a venir a esta canchita a jugar? Les debe parecer descuidada o poca cosa, cuando ya tienen ese campo de tenis al lado. La cancha solo la usamos territarias 43 
la gente del barrio, nadie más (Natalia, residente de San José).

Aquí no hay un punto de encuentro más allá del Condado Shopping, donde sí se reúnen todos. Es imposible que ellos [residentes de San José] entren al Quito Tenis, no se permite la entrada a la gente que no es socia, les negarían el ingreso en la puerta (Jenny, residente de la Urbanización).

Por lo tanto, estos lugares no son percibidos como escenarios claves para el encuentro intergrupal. Primero, porque resultan ser espacios descuidados (como en San José). Segundo, porque en ellos no se acepta a todo público (como en la Urbanización). Pese a lo anterior, no hay que desconocer la posibilidad de interacción a nivel local. En efecto, hay otros espacios locales potenciales para el encuentro intergrupal, como las paradas de buses y los centros comerciales. No obstante, en estos lugares la interacción también es reducida y es poco probable el diálogo entre los estratos, debido a tácticas de reconocimiento del otro que intentan ubicar las jerarquías sociales (Ruiz-Tagle, 2016b). Resulta difícil pasar desapercibido en estos lugares, ya que a partir de la ropa o los gestos se identifican las procedencias del estrato. Algunos residentes de San José dicen que no visitan los centros comerciales sin antes haber mejorado su apariencia corporal. Para ellos, trabajar en el aspecto personal implica no ser ubicados territorias 43 14 la información recabada no permita intuir si estas tácticas constituyen una barrera para la interacción, sí se visibiliza cómo se adoptan modos de enseñar el cuerpo en público: "Siempre con mi esposo nos arreglamos antes de ir [al centro comercial]. ¡Cómo cree que uno va a ir en sandalias! ¡O despeinada y con lagañas! [Risas] Dirían que una es lo peor. Qué vergüenza” (Antonia, residente de San José).

Entonces, haciendo un repaso por los principales espacios de encuentro, se halla que la asistencia a parques y zonas de recreación es segmentada, mientras que la interacción en centros comerciales y paradas de transporte público está mediada por lecturas corporales jerarquizadas. En la figura 2 se detalla la distribución de los espacios potenciales de interacción en el área, donde se incluye también a las escuelas y colegios analizados en el anterior apartado. Se visibiliza cómo, a pesar de haber proximidad espacial entre los grupos, la ubicación de estos espacios resulta clave en las oportunidades de relacionamiento.

Vale aclarar que en el área residencial existen otros espacios potenciales de encuentro. Debido al rechazo conjunto al proyecto Quito Cables, miembros de los diferentes grupos tuvieron posibilidad de encontrarse en marchas, plantones, asambleas o ruedas de prensa. Si bien estas actividades tenían como objetivo principal visibilizar la oposición hacia el proyecto, también permitieron la interacción con el otro, contribuyendo a conocer a las familias afectadas, a intercambiar diálogos 
Figura 2. Espacios potenciales de encuentro en el área de estudio

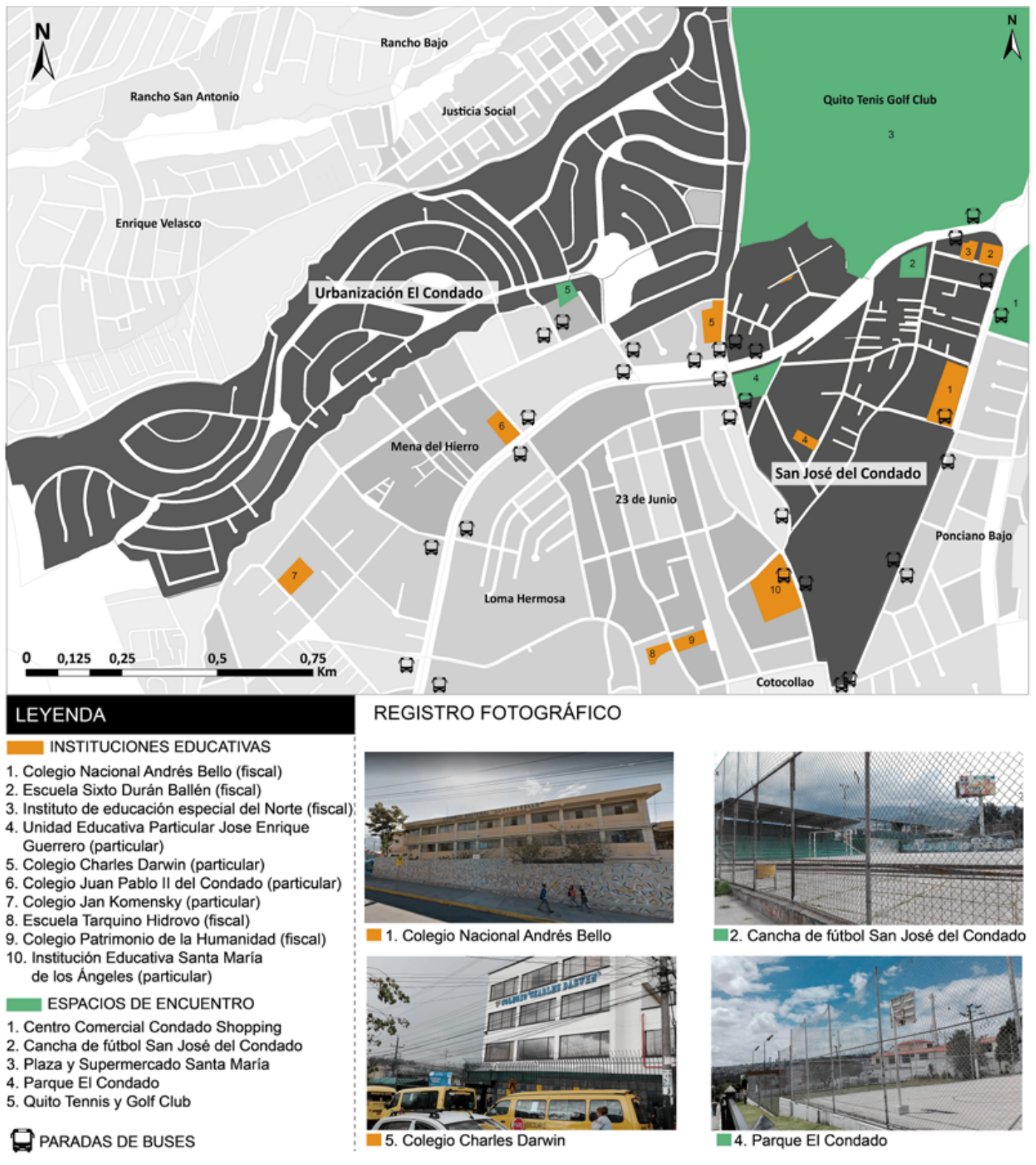

Fuente: elaboración del autor. 
2 El término pelucón, además de ser empleado para identificar a hogares ricos o poseedores de dinero, también denota modos de vida que la posesión de capital monetario permite a estos hogares: compra de autos de lujo, educación en universidades privadas prestigiosaso adquisición de viviendas costosas. Así, cuando los entrevistados de San José se refieren a los habitantes de la Urbanización como pelucones, están definiendo también formas de vida $y$ costumbres culturales con las cuales se diferencian.

\section{territarias 43}

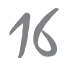

y preocupaciones compartidas. Así mismo, facilitaron tener una percepción distinta del comportamiento del otro en espacios intergrupales: "Yo nunca me imaginé ver a un pelucón ${ }^{2}$ gritando con uno 'No Quito Cables' [risas]" (Natalia, residente de San José). Para los entrevistados, a partir de estos espacios hubo un aumento significativo de interacción. En palabras de Patricio:

Antes la gente no nos encontrábamos para nada. Hoy eso cambió. Hay una interacción y armonía que, por ejemplo, nosotros hacemos una asamblea, o hacemos una feria, y la gente de la Urbanización baja y nos ayuda. O ellos hacen alguna caminata, alguna cosa, y nos invitan y participamos mancomunadamente (Patricio, vocero de San José).

De esta experiencia surgieron nuevos espacios que promovieron el encuentro y el relacionamiento entre los grupos. Como se refiere en otros casos (Levy et al., 2013; Joseph, 2006), la organización y solución de asuntos comunes crearon oportunidades para la interacción basada en conexiones entre vecinos sin importar su condición social. Un aspecto que permite fortalecer los procesos de integración social.

Ahora bien, con respecto a los lazos sociales entre los diferentes grupos, se constata la presencia de algunas relaciones de amistad y de precarias relaciones de vecindad. Empezando con estas últimas, los entrevistados comentan que los vínculos son escasos entre los barrios y dentro de cada vecindario. En la Urbanización se indica que los vecinos no se conocen entre sí, debido a que existe un ambiente caracterizado por el individualismo y la apatía. Asumen que si es complicado construir relaciones entre vecinos de un mismo barrio, lo es más aún hacerlo con hogares de otros barrios:

Sabe que aquí mismo nadie conoce a los vecinos. Yo no sé quién vive aquí al lado, ni enfrente. ¡No sé ni los nombres! O sea, ya cada uno vive en su vida, llegan del trabajo y se encierran. Y se acabó. No hay ninguna relación. Peor con los barrios de afuera, absolutamente nada. Cada uno hace su vida (Rafael, residente de la Urbanización).

Basados en esta autocaracterización, los hogares de la Urbanización perciben a San José como lo opuesto a ellos. Señalan que allí existe un ambiente más de vecindad, donde todos se conocen entre sí. No obstante, los residentes de San José indican lo contrario, ya que consideran que cuesta conocer al vecino. Esto ocurre, fundamentalmente, con los habitantes más jóvenes, pues los antiguos moradores subrayan conocerse entre sí desde hace bastante tiempo. Pero esto cambia a partir del rechazo a Quito Cables, cuando empiezan a conocer a los nuevos vecinos: "Esta pelea unió a todo el barrio. A partir de ella conocí a algunos vecinos que no había visto, y viviendo aquí mismo" (vecinos 
afectados por Quito Cables, residentes de San José).

Justamente, a raíz de Quito Cables ocurre una dinámica de construcción de relaciones de vecindad en el interior de cada barrio, pero también entre los diferentes estratos. Los entrevistados le otorgan un valor importante a esta oposición como generadora de acercamientos vecinales, dado que antes de ella no se relacionaban entre sí, y es a partir de ella que los habitantes de ambos barrios empiezan a reconocerse - e incluso a necesitarse-como vecinos:

Antes de Quito Cables no tenía ese vínculo con los vecinos de San José. Eso me abrió los ojos de que siempre en la vida te pasará algo. Por eso, es muy importante conocer a tus vecinos, para los problemas que tengas a futuro (Lothar, vocero de la Urbanización).

Aunque esta afirmación no pueda generalizarse para todos los residentes, es crucial entenderla en el contexto local marcado por la escasa vecindad. El rechazo conjunto al proyecto generó el interés de propiciar nuevos sentimientos y relaciones vecinales entre los estratos, incluso para visualizar soluciones compartidas a problemas en el futuro.

Ahora bien, la otra faceta de los lazos sociales son las relaciones de amistad. Los residentes consideran que este tipo de relaciones son escasas entre miembros de diferentes estratos, debido a que son vistas como un lazo profundo que se construye entre similares y no con la otredad. Además, resaltan como obstáculo la existencia de una dimensión jerárquica que impide la construcción de lazos entre diferentes en el ámbito residencial. No obstante, reconocen que en algunas ocasiones es posible trascender las barreras que coartan la formación de relaciones. A partir del rechazo a Quito Cables, los voceros de estos barrios y algunos residentes se refieren a una construcción de vínculos sociales más cercanos:

Yo mantengo la relación con todos ellos. Somos panas con todos en realidad. Y amigo específicamente del Patricio. Con él hemos llorado, nos hemos abrazado, hemos salido, hemos hecho de todas las vainas. La gente cuando está en problemas vuelve a lo básico. Que es que somos seres humanos, y no importa qué piensas, si eres de izquierda o de derecha, de arriba o de abajo. ¡No importa! Estamos en problemas y nos juntamos, hasta hacernos panas (Lothar, vocero de la Urbanización).

Sin embargo, este acercamiento entre los residentes de ambos barrios no fue fortuito. Todo obedeció a una relación basada en la confianza. Inicialmente había una imagen -incentivada, entre otras cosas, por el propio gobierno local en medios de comunicación (Narváez, 2018) - en la que los habitantes de la Urbanización querían beneficiarse de los moradores de barrios populares para que no se construyera Quito Cables. Particularmente se decía que los estratos altos se oponían 
a la línea de teleférico para que los pobres no les vieran sus piscinas. Cuando los voceros de la Urbanización fueron a los barrios populares a convocar a la movilización, estos no confiaron en sus intenciones, creyendo que había intereses particulares de por medio. Pero con los constantes acercamientos y la explicación de las deficiencias del proyecto para suplir las demandas de movilidad, los opositores de la Urbanización lograron conseguir credibilidad y confianza:

Cuando ellos vinieron a explicarnos nos dijeron: "El proyecto es malo por esto y esto". Y ya la gente le escucha a Lothar y le cree un montón. Porque al principio la gente decía: "Ah, es que el pelucón no quiere que les veamos sus piscinas, no quiere el progreso para nosotros". Pero ahora ya se piensa diferente (Grace, residente de San José).

Este argumento ilustra cómo no fue fácil transgredir la dimensión jerárquica de las relaciones entre diferentes estratos. Existía la sospecha de que el otro, quien ostenta mayores recursos económicos, podía beneficiarse de la situación para sus intereses personales. Sin embargo, la ilusión de la jerarquía se diluyó cuando se logró posicionar el interés general sobre el particular: y esto ocurrió a partir de repetidos intentos de confianza y claridad con el otro. Es decir, hacerle saber - y demostrarle-que sus intenciones eran sinceras.

\section{territarias 43} 18 entrevistados reconocen que el rechazo a Quito Cables otorgó la posibilidad de construir lazos sociales entre los estratos.

Finalmente, resta por indicar que el ascenso social es visto como elemento perturbador de los lazos sociales. Aunque los entrevistados no conozcan casos particulares, asumen que la nueva población que ha ingresado a la Urbanización puede mantener una conducta jerárquica en sus relaciones de vecindad o amistad, similar a como lo muestra en los contratos laborales. Conducta que no se adapta a comportamientos sociales que propician las interacciones sociales (Joseph, 2006).

\section{Percepción del otro e identidad territorial}

La literatura entiende que la proximidad espacial entre grupos diferentes puede incidir en una integración simbólica en dos sentidos. El primero, en la reducción de estigmas territoriales y calificativos negativos hacia el otro (Sabatini \& Salcedo, 2007). El segundo, en la conformación de identidades territoriales, las cuales implican un grado de apego y compromiso que sienten los residentes hacia el lugar en el que viven (Ruiz-Tagle, 2013; Sabatini \& Salcedo, 2007; Morandé, 2007). En los siguientes párrafos se discuten estos dos supuestos, además de que se introduce el vínculo político como elemento de reflexión.

En cuanto a los calificativos, los entrevistados tienen apreciaciones positivas 
de los residentes del vecindario aledaño: generalmente la presencia del otro no incomoda ni molesta. En la Urbanización reconocen que los habitantes de San José no son pobres, ya que se considera una población propietaria que ha podido superarse a partir de años de esfuerzo y trabajo. Y se califican así porque se reconoce que fueron ellos mismos quienes produjeron su barrio. Así mismo, desde su visión, San José no carga con el peso del estigma territorial, puesto que no es considerado un barrio peligroso, y en caso de asaltos no es el primero en ser señalado. Primero, porque el ladrón puede provenir de cualquier parte de la ciudad. Segundo, porque se piensa que el peligro puede haber emanado de barrios populares de menor reputación. Esta visión también la comparten los residentes de San José, quienes ubican a los agentes peligrosos fuera de su barrio, reiterando la imagen que se posee en toda el área residencial sobre un 'otro lejano' negativo:

No, con San José no ha pasado nada. La gente de ahí es humilde y trabajadora. Por ahí se escucha que quienes roban son la gente de Pisulí o La Roldós. ${ }^{3}$ Y no sé, me imaginó que sí (Jenny, residente de la Urbanización).

No es por hablar mal, pero la gente de La Roldós y Pisulí es la gente de más bajo nivel social que existe en el noroccidente de Quito. Son barrios ilegales, de negros, asaltantes, de borrachos, de marihuaneros (Natalia, residente de San José).

Por su parte, los hogares de San José expresan que quienes viven en la Urbanización son pelucones. Este calificativo, además de ser empleado para identificar a hogares adinerados, también se utiliza para definir formas de vida y costumbres culturales con las cuales se diferencian: compra de autos de lujo, educación en universidades privadas prestigiosas, entre otras. Sin embargo, reconocen que no todos los residentes de la Urbanización son pelucones. En algunas ocasiones también son personas de apariencia. Es decir, habitantes que viven en un barrio adinerado, pero que no tienen dinero y no demuestran sus costumbres. Esto último está enfocado principalmente a retratar a los nuevos habitantes en ascenso social que arribaron a la urbanización, percepción que incluso también es compartida por sus propios moradores. Así, quienes se encuentran en los polos de la estratificación social identifican la existencia de una clase media que aspira a ser similar al polo más alto, pero sin lograrlo.

Ahora, la imagen de pelucón se transformó a raíz del rechazo a Quito Cables. Como se indicó en el anterior apartado, inicialmente había una imagen en la que los habitantes de la Urbanización querían beneficiarse de los moradores populares para que la línea de teleférico no pasara sobre sus supuestas piscinas. Una conducta que era calificada como "típica de
${ }^{3}$ Pisuli y La Roldós son barrios del noroccidente de Quito cuya historia está asociada a la toma ilegal de terrenos y sus habitantes son llamados ilegales. territarios 43

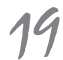


los pelucones", pues con ella mostraban defender solamente sus intereses y modo de vida, sin preocuparse por solucionar los problemas de movilidad de los estratos bajos. Los voceros de la Urbanización consideran que esta era una visión errónea que el municipio ponía sobre ellos y que buscaba desviar la atención de lo perjudicial que era el proyecto. Señalan que hubo una estrategia de separación donde el municipio recurrió a factores de clase para denunciar que los culpables de la no construcción de Quito Cables eran los pelucones. En las entrevistas a residentes de San José, se identifica un discurso inicial en el que ellos consideraban, a partir de esta estrategia del municipio, que los residentes de la Urbanización no querían el progreso y el bienestar del noroccidente de Quito. Esta percepción comienza a cambiar cuando ocurren los acercamientos, diálogos e intercambio de información entre todos los implicados:

Vecino 1: el alcalde quiso utilizar eso de las clases sociales para dividirnos. Diciendo que desde la Urbanización nos estaban manipulando. Venía gente del municipio a decirnos: "Es que no le hagan caso a Lothar. ¿̨Por qué le hacen caso? Si es que él vive bien, tiene una casa grande, a él no le afecta”. Ese fue el discurso del municipio, de que los ricos están en contra de Quito Cables porque no querían que les vieran sus piscinas.

\section{territarias 43}

Vecino 2: pues para generar odio, para sembrar esa división, nada más [todos asienten].
Vecino 3: claro, pretendían dividirnos y hacernos ver que estábamos manipulados. Pero poco a poco nos dimos cuenta de que el proyecto estaba plagado de corrupción y que tampoco nos iba a resolver el problema de movilidad. Así supimos que no solo debíamos pelear para que no nos expropiaran la casa, sino porque el proyecto no sirve (vecinos afectados por Quito Cables, residentes de San José).

Los entrevistados manifiestan que a partir de las interacciones intergrupales se reveló el verdadero interés de Quito Cables. Sostienen que, aparte de la expropiación de predios y la construcción de pilonas, es un proyecto planteado sin estudios técnicos, sin alternativas, no socializado con la comunidad y direccionado para que solamente una empresa lo construyera. Más allá de describir las reivindicaciones por las cuales ambos barrios lo rechazaron, interesa resaltar que es a partir de ellas que empieza a transformarse la percepción sobre el otro. Por un lado, empieza a ser desmentida la imagen de los estratos altos como pelucones que no querían el progreso para los pobres. En San José comenzó a verse a los habitantes de la Urbanización más como aliados estratégicos que como enemigos, y aunque no dejan de ser llamados pelucones, ahora se refieren a ellos como personas amables y comprometidas con causas comunes. Por el otro, los residentes de la Urbanización reconocen que el contacto con moradores de San José amplió las referencias que tenían antes. 
Ahora también los definen como gente profesional, y como una población que está constantemente superándose. Ambas valoraciones sugieren la existencia de discursos que confieren una mirada menos antagónica de los estratos sociales. Así, el rechazo a Quito Cables generó la posibilidad de ampliar la percepción del otro y, a su vez, creó la opción de autodefinirse en el marco de oposición conjunta, de varios estratos. En palabras de Patricio:

Lo único que debemos agradecerle al [alcalde] Rodas es que creó unión de barrios y de clases sociales. Aquí ya no hay pelucones de la Urbanización El Condado ni hay pobres de San José del Condado. Todos somos lo mismo. Todos vivimos aquí (Patricio, vocero de San José).

Este testimonio sugiere que, a partir de Quito Cables, se presenta una búsqueda por reducir la distancia simbólica entre los estratos. Y esto en dos sentidos. El primero, en función de la proximidad espacial y las oportunidades: aunque se reconozca la diferencia del capital económico, los entrevistados se perciben como habitantes de un mismo lugar — "todos vivimos aquí"-, quienes se encuentran en un camino común en el que intentan superar su problemáticas. El segundo, como una respuesta política: se resalta la 'unión de barrios y de clases sociales' como una estrategia discursiva para visibilizar que, pese a la presencia de varios estratos, fue posible aunar esfuerzos para un rechazo común. En todo caso, en ambas visiones se exalta la proximidad física que estructura la residencia.

Ahora bien, con respecto a la conformación de identidades territoriales, se descubre que el rechazo a Quito Cables provocó dos procesos simbólicos. Por un lado, se acrecentaron los sentimientos de apego y compromiso que los residentes tienen con su propio vecindario. $Y$, por el otro, se incentivó la identificación común con toda el área residencial.

En cuanto al primer proceso, en San José los vecinos describen que volvió a surgir la lucha vecinal que ha caracterizado la historia del barrio. Desde su fundación sus residentes se organizaron para construir calles o para oponerse a proyectos públicos. Esta experiencia organizativa es percibida como un aspecto útil que benefició a los habitantes de la Urbanización, puesto que ellos "tan solo eran un puñado que no tenían práctica movilizándose en contra del municipio" (vecinos afectados por Quito Cables, residentes de San José). A su vez, la lucha vecinal estimuló el grado de apego se sus residentes, ya que estos renuncian a irse del barrio aun cuando el gobierno local les ofrezca más dinero por la expropiación de sus predios: para ellos, las historias, sus viviendas autoproducidas y la vida social construida en el barrio resultan tener mayor valor. Por su parte, los residentes de la Urbanización consideran más significativo defender el ambiente de tranquilidad y privacidad que tiene su vecindario: "Eso quiere uno, vivir territarias 43 
tranquilamente, que nadie le moleste y no molestar a nadie. Llegar a descansar, es lo que se quiere nada más. Y con este proyecto eso iba a ser difícil" (Jaqueline, residente de la Urbanización). Así, para ellos, no hay una historia de lucha o relaciones vecinales que les incite a quedarse en la urbanización, sino sus fines son más simbólicos y prácticos: quedarse allí reafirma su estatus y conserva sus estilos de vida.

En cuanto al segundo proceso - es decir, la identificación con el territorio común-, los entrevistados resaltan la construcción de nuevas formas de entender la residencia en el noroccidente de Quito. Para ambos vecindarios, el área residencial que comparten es importante debido a su localización (es uno de sectores de más alta valorización predial de la ciudad), su funcionalidad (cercanía a principales vías y centros comerciales de la ciudad) y diversidad social (existencia de varios estratos sociales en condición de proximidad espacial). Perciben que fueron estos valores los que intentó quebrantar Quito Cables y que, de tal modo, buscaron defender con su oposición. Esta defensa intergrupal del territorio es visible a partir del uso de grafitis y afiches alusivos a "No Quito Cables", que fue el frente y la frase con la que ambos barrios manifestaron su rechazo al proyecto. No obstante, aunque hayan compartido este lema, la forma con la cual cada barrio visibilizó su oposición se expresó de manera diferente. En San José se acudió a pintar paredes con grafitis territarios 43 22 la Urbanización, en cambio, se acudió a pequeños afiches en las ventadas de las viviendas con el lema y, además, a representar una de las pilonas del teleférico (figura 4).

A partir de esta identificación común con el territorio, también surge la elaboración de una propuesta propia para solucionar los problemas de movilidad que presenta el noroccidente de Quito. San José y la Urbanización, junto con los demás barrios implicados en el proyecto, plantearon una alternativa a Quito Cables, la cual consistió en darle prioridad al mejoramiento de barrios y a la culminación y ampliación de las actuales vías. Para ellos, esta es una propuesta más económica que no implica la expropiación de predios ni el paso de la línea del teleférico por viviendas. Sin embargo, esta propuesta fue rechazada por el municipio. Quito Cables pasó por distintas denuncias, juicios y seguimientos, donde se reclamó la restitución de los predios expropiados, mayor participación ciudadana y la aplicación de propuestas alternativas al proyecto (Narváez, 2018). A nivel de la ciudad, otros proyectos del exalcalde Rodas generaron controversias. Sobre este entendido, quienes estuvieron más involucrados en la oposición a Quito Cables buscaron ampliar su lucha a un plano urbano, apoyando el proceso de revocatoria del alcalde que diversos colectivos lideraban. Para ellos, luego de haber actuado para defender el área del proyecto, el siguiente paso era "darle la muerte política al [exalcalde] Rodas" (vecinos 
Figura 3. Rechazo a Quito Cables en San José
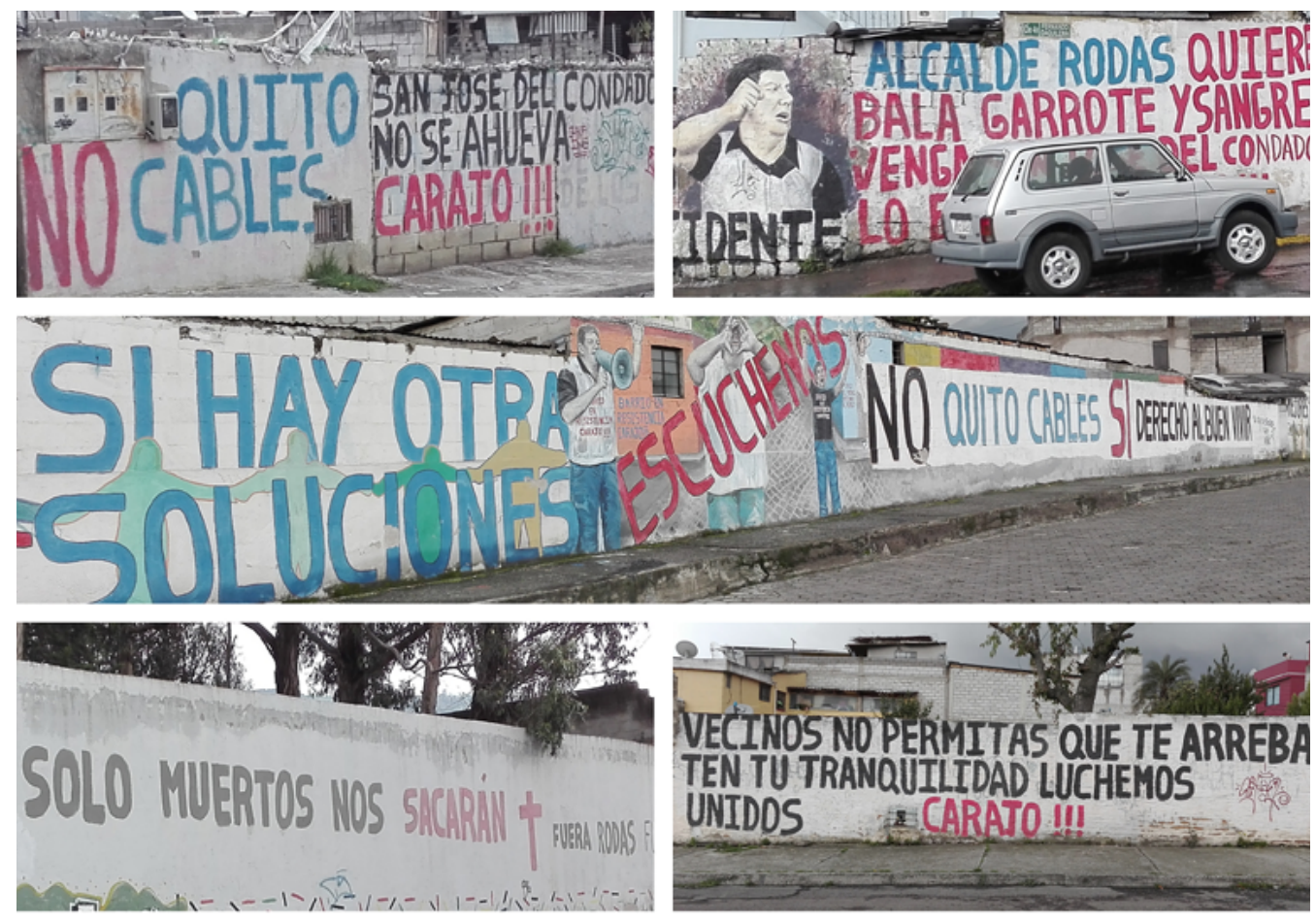

Fuente: archivo personal.

afectados por Quito Cables, residentes de San José). ${ }^{4}$

Finalmente, resta por indicar otro aspecto de la identidad territorial en el área. Este tiene que ver con que en el interior de la Urbanización se reconoce la existencia de identidades diferentes con los recién llegados, es decir, con la nueva clase media que ha arribado al vecindario: esta es vista como una población que solo asume el espacio para aparentar. Por consiguiente, es una población que busca beneficiarse del capital simbólico con el que disponen estos lugares, pero sin dar nada a cambio, ya que no participa en procesos de organización o contribuye a su realce.

\section{Discusión y conclusiones}

Este artículo caracterizó los procesos de integración que acontecen entre hogares de distinta condición socioeconómica en un área socialmente diversa de Quito. Se preocupó por describir la configuración de vínculos sociales que suceden en el
${ }^{4}$ Al momento en que se escribe este articulo, el proceso de revocatoria del alcalde se encuentra en curso. El formulario de recolección de firmas es repartido y llenado por residentes de San José y de la Urbanización.

territarios 43

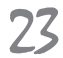


Figura 4. Rechazo a Quito Cables en la Urbanización
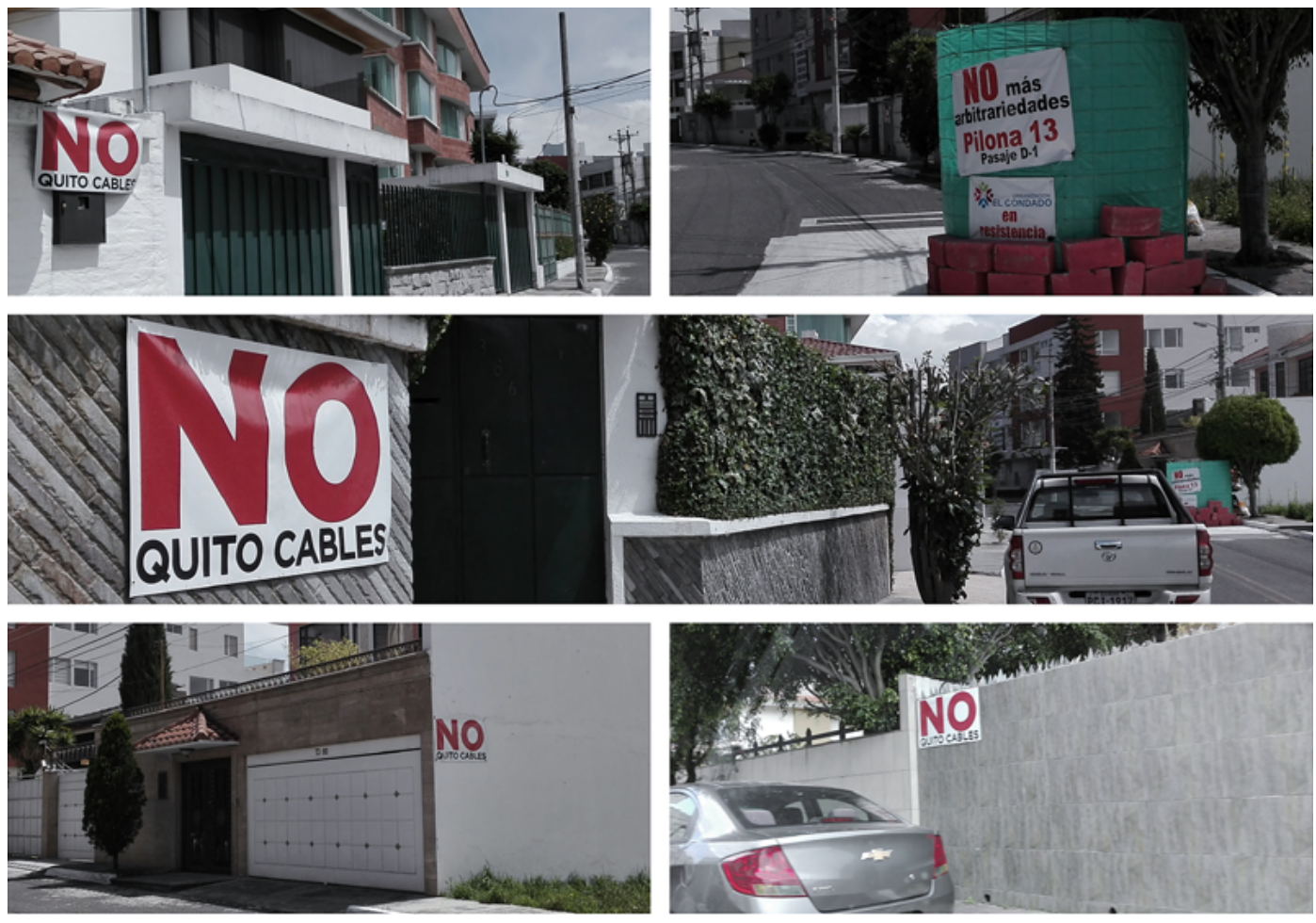

Fuente: archivo personal.

plano funcional (oportunidades educativas y laborales), relacional (interacciones en público y relaciones de amistad y vecindad) y simbólico (calificativos hacia el otro e identificación con el territorio). Lo hallado en estas tres dimensiones permite dialogar con la hipótesis planteada, la cual consideraba que a partir de respuestas políticas y alianzas intergrupales los grupos se beneficiaban simbólicamente, más no funcional ni relacionalmente. Así, territorios 43 24 los hallazgos del artículo aportan a la corriente teórica crítica de la integración, esto en la medida que se entiende que la proximidad espacial de los grupos no se traduce automáticamente en vínculos sociales ni en geografías de oportunidades.

En efecto, los procesos de integración socioespacial entre San José y la Urbanización revelan que la proximidad entre grupos diferentes no deriva en acceso a oportunidades y servicios, o en mayores probabilidades de encuentro en espacios públicos. Sin embargo, en estos últimos, 
el acercamiento que hubo entre diversos estratos alrededor de una causa común como fue el rechazo a Quito Cables permitió que se generaran nuevos espacios de interacción y nuevas relaciones de amistad y vecindad. Pero la misma respuesta política intergrupal no logró alterar el acceso efectivo a las oportunidades educativas y laborales.

El caso analizado advierte cómo el acceso común a servicios educativos está mediado tanto por las fronteras económicas y simbólicas que producen los costos de matrícula y pensión, como también por la búsqueda de instituciones de prestigio. Los distintos grupos no buscan instituciones en donde asistan niños de diferentes estratos, sino se interesan más por aquellas que les permitan elevar su capital escolar y simbólico. Así mismo, el caso ilustra que convivir en el mismo espacio residencial no necesariamente involucra que existan más oportunidades laborales entre los grupos. Por un lado, las posibilidades de empleo que ofrecen los barrios de estratos altos generalmente cubren una demanda laboral que se distribuye espacialmente por toda la ciudad. Y, por el otro, los estratos bajos recurren a otros empleos o al autoempleo.

Por su parte, en la dimensión relacional, el caso introduce otros espacios para el encuentro poco considerados en la literatura existente, dado que las asambleas y movilizaciones también son espacios potenciales para la interacción. Empero, para que estos tengan lugar, debe haber una temática o reivindicación compartida que convoque a los grupos. Por lo demás, el caso reafirma que son escasas las probabilidades de encuentro en espacios públicos. Las interacciones aquí se desarrollan más de una forma intragrupal que intergrupal, ya que cada grupo tiene su propio lugar para la recreación. Igualmente, en centros comerciales y paradas de bus, aunque haya una concurrencia intergrupal más probable, el otro es constantemente identificado, al punto en que se adoptan comportamientos y vestimentas ejemplares para no ser ubicado en categorías inferiores.

Del mismo modo, el caso aclara que a raíz de una reivindicación puntual y común puede germinar el interés por propiciar nuevos lazos sociales entre residentes de diferentes estratos. Si no existieran estas reivindicaciones, la proximidad espacial no lograría por sí misma incidir en la configuración de relaciones vecinales o amistosas entre los grupos. Por un lado, resulta más probable construir lazos entre similares. Se entiende que las jerarquías sociales son obstáculos para construir relaciones entre diferentes. Por el otro, el espacio no es la primera referencia para que esto suceda. Los acercamientos prolongados y sinceros se valoran más que el hecho de compartir fronteras residenciales.

En cuanto a la dimensión simbólica, el caso revela que la proximidad y la convivencia positiva entre grupos sí inciden positivamente en la reducción de calificativos negativos hacia el otro y de estigmas territoriales. Sin embargo, también pone a consideración cómo desde esta 
proximidad circulan percepciones que les confieren marcas negativas a lugares populares periféricos, a la par que le asignan grados de peligrosidad a sus residentes. El 'otro cercano' resulta menos peligroso y más dispuesto a ser aceptado que el 'otro lejano'. Igualmente, se muestra cómo la conformación de una identidad territorial común entre diferentes grupos requiere que ambos se involucren en actividades de defensa conjunta del territorio. De lo contrario, la identidad tiende a ser fragmentada.

Como eje transversal, el caso analizado muestra que la presencia de la clase media tiende a distorsionar todas las dimensiones de la integración. Los precarios, inexistentes o florecientes vínculos sociales entre los polos sociales no provocan mayores disgustos. Estos ocurren, más que nada, con los nuevos residentes que arriban a la Urbanización. Se entiende que este grupo empobrece la integración funcional a través de vínculos de empleo inequitativos, complica la integración relacional a partir de conductas jerárquicas en las relaciones de vecindad y amistad, y entorpece la integración simbólica debido al uso del espacio solamente como apariencia. Por lo tanto, una agenda de investigación futura debe abordar a mayor detalle qué papel desempeña la clase media en los contextos de proximidad espacial y en los procesos de integración social.

A manera de síntesis, el área de San José y la Urbanización evidencia cómo los procesos de integración socioespacial son dispares en todas sus dimensiones, siendo necesario por consiguiente cuestionar sus supuestos. Además, se constata que la integración no puede ser vista como una convivencia armónica, sino que debe ser leída en medio de un contexto de conflicto, donde se gestionan las asimetrías de poder, las desigualdades y diferencias a partir de procesos de acercamiento social. La presencia o ausencia de una amenaza compartida es un factor que incide en este acercamiento, el cual activa procesos de integración a partir de respuestas políticas y alianzas intergrupales que privilegian más el espacio compartido que la diferencia socioeconómica. Si bien estos lazos no logran limar las disparidades socioeconómicas, ni tampoco cuestionan el acceso desigual a oportunidades y servicios, terminan por ejercer una presión social para la construcción de relaciones intergrupales y la conformación de identidades territoriales y sentidos de pertenencia compartidos. No obstante, estas prácticas de acción colectiva no deben exagerar la importancia del espacio para reducir las condiciones de desigualdad entre los grupos, puesto que las brechas sociales no solo no pueden ser superadas con la proximidad, sino que tampoco se alteran o cuestionan con los procesos de acercamiento social que de ella se pueden derivar. Se invita a que una agenda futura de investigación incorpore la acción colectiva y la desigualdad dentro de los estudios de mezcla social. 
De la misma manera, el caso de Quito invita a leer la integración sin los supuestos que ponen el énfasis en un solo grupo y no contemplan la agencia de los hogares de menores ingresos. La literatura resulta ver con optimismo los beneficios y oportunidades que se desprenden para los hogares pobres en cercanía a hogares ricos. Tras estos hallazgos, aquí se sostiene que esta mirada vertical de arriba-abajo puede ser cambiada, ya que los grupos altos también pueden experimentar 'beneficios' con la cercanía de estratos bajos. Más allá de la prestación de servicios laborales o de comercios de pequeña escala (tradicionalmente considerados en la literatura como servicio por intercambiar), los barrios populares en las urbes latinoamericanas tienen una historia de lucha que los han hecho acumular experiencia organizativa, la cual puede ser considerada como beneficio local en las áreas de mezcla social. Los grupos medios y altos pueden 'beneficiarse' de ella cuando los problemas del área no puedan ser solucionados por sus propios recursos y métodos convencionales. Así, se invita a reflexionar la integración socioespacial en la región desde el vínculo político, sin el sesgo jerárquico de arriba-abajo que la ha caracterizado hasta nuestros días, más aún en la actualidad cuando se multiplican en las ciudades los conflictos sociales y ambientales por la instalación de distintos proyectos urbanísticos de tipo NIMBY (Not in my back yard).

\section{Referencias}

Achig, L. (1983). El proceso urbano de Quito. Centro de Investigaciones Ciudad.

Basolo, V. (2013). Examining mobility outcomes in the Housing Choice Voucher Program: neighborhood poverty, employment, and public school quality. Cityscape, 15(2), 135-154. Recuperado de https://www.huduser.gov/portal/periodicals/cityscpe/voll5num2/ chl0.pdf

Bell, W. (1954). A probability model for the measurement of ecological segregation. Social Forces, 32(4), 357-364. https:// doi.org/10.2307/2574118

Bermúdez, N., Cabrera, S., Carrión, A., Hierro, S., Echeverría, J., Godard, H., \& Moscoso, R. (2016). La investigación urbana en Ecuador (1990-2015): cambios y continuidades. En P. Metzger, J. Rebotier, J. Robert, P. Urqueita \& P. Vega, La cuestión urbana en la Región Andina: miradas sobre la investigación y la formación (pp. 117-173). Quito: PUCE. Recuperado de http://www.ifea. org.pe/libreria/hors-collection/pdf/ cuestion-urbana-region-andina.pdf

Bolt, G., Phillips, D., \& Van Kempen, R. (2010). Housing policy, (de) segregation and social mixing: an international perspective. Housing Studies, 25(2), 129-135. https://doi. org/10.1080/02673030903564838

Bryman, A. (2007). Barriers to integrating quantitative and qualitative territarias 43 


\section{territarias 43} 28 research. Journal of Mixed Methods Research, 1(1), 8-22. https://doi. org/10.1177/2345678906290531

Carrión, D., Rodríguez, A., Carrión, F., Guayasamin, H., \& García, J. (1978). Quito: renta del suelo y segregación urbana. Colección Premio, Ediciones Quito.

Carrión, F. (1987). Quito, crisis y politica urbana. El Conejo-Ciudad.

Chaskin, R., \& Joseph, M. (2010). Building "community" in mixed-income developments. Assumptions, approaches, and early experiences. Urban Affairs Review, 45(3), 299-335. https://doi. org/10.1177/1078087409341544

Colomb, C. (2011). Urban regeneration policies of "social mixing" in Brithis cities: a critical assessment. Architecture, City and Environment, 6(17), 223-244. https://doi.org/10.5821/ ace.v6il7.2535

DeFilippis, J. (2013). On spatial solutions to spatial problems. Cityscape, 15(2), 69-72. Recuperado de https://www. huduser.gov/portal/periodicals/cityscpe/voll5num2/ch4.pdf

DeLuca, S., Duncan, G., Keels, M., \& Mendenhall, R. (2012). The notable and the null: using mixed methods to understand the diverse impacts of residential mobility programs. En M. van Ham, D. Manley, N. Bailey, L. Simpson \& D. Maclennan, Neighbourhood effects research: new perspectives (pp. 195-224). Dordrecht: Springer. Recuperado de https://link.springer.com/chapter/10.1007/978-94-007-2309-2_9 Durán, G., Martí, M., \& Mérida, J. (2016). Crecimiento, segregación y mecanismos de desplazamiento en el periurbano de Quito. Íconos. Revista de Ciencias Sociales, 56, 123-146. https://doi. org/10.17141/iconos.56.2016.2150

Ferro, G. (2010). Guía de observación etnográfica y valoración cultural a un barrio. Apuntes, 23(2), 182-193. Recuperado de http://www.scielo.org. co/pdf/apun/v23n2/v23n2a07.pdf

Fraser, J., Chaskin, R., \& Bazuin, J. (2013). Making mixed-income neighborhoods work for low-income households. $\mathrm{Ci}$ tyscape, 15(2), 83-100. Recuperado de https://www.huduser.gov/portal/ periodicals/cityscpe/voll5num2/ch6. pdf

Gerring, J. (2007). What is a case study and what is it good for? American Political Science Review, 98(2), 341354. https://doi.org/10.1017/ S0003055404001182

Guber, R. (2004). El salvaje metropolitano. Reconstrucción del conocimiento social en el trabajo de campo. Paidós.

Imbroscio, D. (2012). Beyond mobility: the limits of liberal urban policy. Journal of Urban Affairs, 34(1), 1-20. https://doi.org/10.1111/j.14679906.2011.00578.x

Instituto Nacional de Estadísticas y Censos (INEC). (2010). Censo de población y vivienda. Recuperado de http://www. 
ecuadorencifras.gob.ec/base-de-datoscenso-de-poblacion-y-vivienda-2010/ Joseph, M. (2006). Is mixed-income development an antidote to urban poverty? Housing Policy Debate, 17(2), 209-234. https://doi.org/10.1080/10511482. 2006.9521567

Kearns, A., McKee, M., Sautkina, E., Weeks, G., \& Bond, L. (2013). Mixed-tenure orthodoxy: practitioner reflections on policy effects. Cityscape, 15(2), 47-68. Recuperado de https://pdfs.semanticscholar.org/b2a8/1431d67a25b27da7 $218 \mathrm{e} 24 \mathrm{~d} 2 \mathrm{bd} 53 \mathrm{fe} 25 \mathrm{~b} 72 \mathrm{a} . \mathrm{pdf}$ ?

Kingman, E. (2006). La ciudad y los otros: Quito 1860-1940. Higienismo, ornato y policía. Flacso Ecuador.

Levy, D., McDade, Z., \& Bertumen, K. (2013). Mixed-income living: anticipated and realized benefits for low-income households. Cityscape, 15(2), 15-28. Recuperado de https:// www.huduser.gov/portal/periodicals/ cityscpe/voll5num2/chl.pdf

López, N. (2012). Nayón, entre lo rural y lo urbano: segregación socioespacial y conflictos entre pobladores (Tesis de maestría, Flacso Ecuador).

López, C. (2017). Movilidad residencial de la élite. Pasado y presente de la élite quiteña, Urbanización Jacarandá 1970-2016 (Tesis de maestría, Flacso Ecuador).

Molinatti, F. (2013). Segregación residencial e inserción laboral en la ciudad de Córdoba. EURE, 39(117), 117-145.
https://doi.org/10.4067/S025071612013000200006

Morandé, M. (2007). Integración social en el espacio y posibilidades de convivencia entre grupos de bajos y altos ingresos. El caso de El Bosque de la Villa en Las Condes (Tesis de maestría, Pontificia Universidad Católica de Chile).

Musterd, S., \& Ostendorf, W. (2006). Segregation, concentration and integration. Critical reflexions on policies and perceptions. The Indian Geographical Journal, 81(2), 81-84.

Narváez, J. (2018). ¿El proyecto de movilidad "Quito Cables": conflicto o solución? (Tesis de pregrado, Universidad Politécnica Salesiana).

Parrado, C. (2018). Segregación en Quito 2001-2010. Evolución de la concentración de los grupos y composición social de las áreas residenciales. Cuestiones Urbanas, 5(1), 61-88. Recuperado de https:// www.academia.edu/38171854/ Segregaci \% C 3\% B 3 n_en_Quito_2001-2010._Evoluci\%C3\%B3n_ de_la_concentraci\%C3\%B3n_de_los_ grupos_y_composici\%C3\%B3n_social_de_las_\%C3\%Alreas_residenciales

Rasse, A. (2015). Juntos pero no revueltos. Procesos de integración social en fronteras residenciales entre hogares de distinto nivel socioeconómico. EURE, 41(122), $125-143$. https://doi.org/10.4067/S025071612015000100006 territarias 43 
Regalado, F. (2015). Origen estructural de la segregación en Quito: una hipótesis. Cuestiones Urbanas, 3(1), 73-91.

Rodríguez, J., \& Arriagada, C. (2004). Segregación residencial en la ciudad latinoamericana. EURE, 29(89), 5-24. https://doi.org/10.4067/S025071612004008900001

Ron, J. (2012). El impacto de las megaestructuras del capital: el caso del mall Condado Shopping (Tesis de maestría, Flacso Ecuador).

Ron, K. (2017). La producción social del espacio en el periurbano del Distrito Metropolitano de Quito: Calderón de lo rural a lo urbano (Tesis de maestría, Flacso Ecuador).

Rosenbaum, J., Reynolds, L., \& DeLuca, S. (2002). How do places matter? The geography of opportunity, selfefficacy and a look inside the black box of residential mobility. Housing Studies, 17(1): 71-82. https://doi. org/10.1080/02673030120105901

Ruiz-Tagle, J. (2013). A theory of sociospatial integration: problems, policies and concepts from a US perspective. International Journal of Urban and Regional Research, 37(2), 388-408. https://doi.org/10.1111/j.14682427.2012.01180.x

Ruiz-Tagle, J. (2016a). La segregación y la integración en la sociología urbana: revisión de enfoques y aproximaciones críticas para las políticas públicas. INVI, 31(87), 9-57. Recuperado de http:// www.revistainvi.uchile.cl/index.php/ INVI/article/view/1070

Ruiz-Tagle, J. (2016b). La persistencia de la segregación y la desigualdad en barrios socialmente diversos: un estudio de caso en La Florida, Santiago. EURE, 42(125), 81-108. Recuperado de http://www.eure.cl/index.php/ eure/article/view/1330

Sabatini, F., \& Salcedo, R. (2007). Gated communities and the poor in Santiago, Chile: functional and symbolic integration in a context of aggressive capitalist colonization of lower-class areas. Housing Policy Debate, 18(3), 577-606. https://doi.org/10.1080/ 10511482.2007.9521612

Sabatini, F., Wormald, G., Sierralta, C., \& Peters, P. (2010). Segregación residencial en Santiago: tendencias 1992-2002 y efectos vinculados con su escala geográfica. En F. Sabatini, R. Salcedo, G. Wormald \& G. Cáceres, Tendencias de la segregación en las principales ciudades chilenas (pp. 19-41). Santiago de Chile: Pontificia Universidad Católica de Chile.

Sabatini, F. (2015). La ruptura del patrón de segregación y su significado teórico y práctico. En M. Porrúa \& I. Escamilla, Segregación urbana y espacios de exclusión: ejemplos de México y América Latina (pp. 25-46). UNAM.

Sánchez, L. (2012). ¿¿Viviendo cada vez más separados? Un análisis multigrupo de la segregación residencial en la 
Ciudad de México, 1990-2005. Estudios Demográficos y Urbanos, 27(1), 57-93. https://doi.org/10.24201/ edu.v27il.1405

Santillán, A. (2015). Quito: materialidad y ficción de una ciudad segregada. Un balance de la bibliografía disponible. Cuestiones Urbanas, 3(1), 93-115.
Torres, E. (2015). Estudio del fraccionamiento urbano-social producido por urbanizaciones cerradas y conjuntos privados en la ciudad de Quito: caso Urb. El Condado (Tesis de pregrado, Universidad Central del Ecuador). 